\title{
界面活性剂水溶液の境界層遷移に関する可視化実験
}

\section{Visual Study on Boundary Layer Transition of an Aqueous Surfactant Solution}

\author{
○学 樋口万希子（名エ大院） 正 伊藤基之（名エ大）
}

\author{
MakikoHiguchi, Nagoya Institute of technology. Gokiso-cho,Showa-ku,Nagoya \\ Motoyukiltoh, Nagoya Institute of tech.
}

Key Words: Laminar-Turbulent Transition, Flat-plate Boundary Layer, Surfactant Solution, Flow Visualization

\section{1. 緒言}

ある種の界面活性剤水溶液は、乱流状態において著しい摩 擦抗力减少を示寸ことが知られているが、そのメカニズムは 末だ十分に解明されるに至っていない。遷移の研究は乱流発 生のメカニズムを知る上でも重要である。そこで本研究では 界面活性剂水溶液の乱流抵抗減少メカニズムの説明の一助 とするため、平板上層流境界層中で人工的に加えたかく乱を 増幅させ、遷移過程が界面活性剂水溶液の場合とニュートン 流体の場合とでどのように異なるかを流れの可視化実験に より調べた。

\section{2. 主な記号}

$\mathrm{f}^{*}$ : 無次元周波数 $\left(=\mathrm{f} v / \mathrm{U}^{2}\right)$

$\mathrm{Re}_{\mathrm{x}}$ : レイノルズ数 $(=\mathrm{Ux} / v) \mathrm{T}$ : 流体の温度

$\mathrm{U}$ : 主流速度 $\mathrm{u}_{\mathrm{ave}}$ : 流れ方向平均速度

$\mathrm{x}:$ テストプレート前縁からの流れ方向距離

$\mathrm{y}$ : 壁面からの垂直距離

$\mathrm{z}$ : テストプレート中心からのスパン方向距離

$\dot{\gamma}$ : せん断速度 $\eta$ : せん断粘度 $\quad v$ : 動粘度

\section{3. 実験装置および方法}

Fig. 1 に実験で用いたアクリル製の開水路測定部を持つ回 流水槽の概略図を示す。実験は主流速度を $U \doteqdot 100 \mathrm{~mm} / \mathrm{s}$ のも とで行った。測定用平板はアクリル製で、直径 $2 \mathrm{~mm}$ のステ ンレス製のワイヤーを前縁から $500 \mathrm{~mm}$ 下流の位置で壁に垂 直方向に周波数 $2 \mathrm{~Hz}$ と $6 \mathrm{~Hz}$ で振動させた。渦の可視化には 水素気泡法を用い、上方または側方から CCD ビデオカメラ により可視化画像を撮影した。画像より陰極線に近い 2 本の タイムラインから速度データを得た。本実験に用いた界面活 性剂水溶液は陽イオン界面活性剤のテトラデシルトリメチ ルアンモニウムブロマイドとサリチル酸ナトリウムの同モ
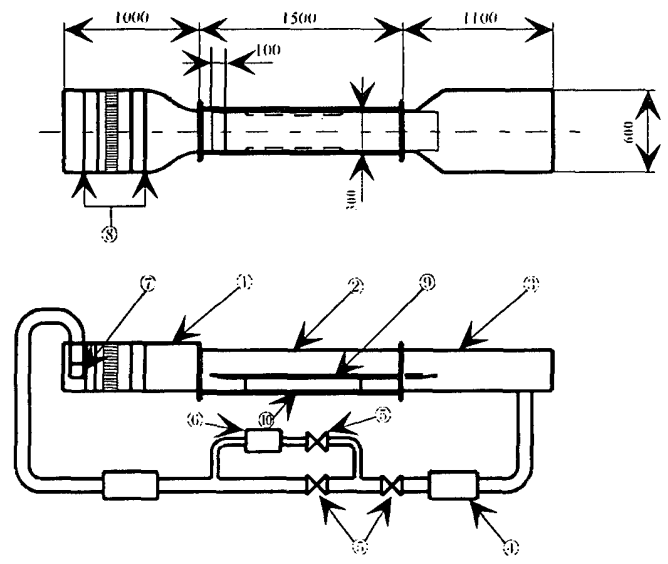

(1) Inlet Tank (2) Acryl Channel (3) Outlet Tank (4) Pump (5) Valve (i) Filter (7) Distribution Manifold Straightener (i) Test Plate (ii) Support
ル量を、イオン除去した純水中に混合したものであり、濃度 400ppmのものを使用した。

\section{4. 実験結果および考察}

4-1 せん断粘度 Fig.2に内径 5.07mm の細管粘度計で測定し たせん断粘度を示す。界面活性剤水溶液はあるせん断速度以 上で SIS(Shear Induced State, せん断誘起状態)を起こし粘度が 上昇することが知られており(1)、今回使用した界面活性剤水 溶液は水に比べて最大でおよそ 1.2 倍までせん断粘度が上昇 した。

4-2 乱流遷移過程の可視化実験 壁面に平行かつ流れ方向に 垂直に陰極線を設置し、水素気泡を連続的に発生させ、上方 から撮影した可視化画像を Fig. $3(2 \mathrm{~Hz}) 、 F i g .4(6 \mathrm{~Hz})$ に示寸。 (a)は水の場合、(b)は界面活性剂水溶液の場合であり、陰極 線の高さはともに $\mathrm{y}=3 \mathrm{~mm}$ である。Fig.3(a)では $\Lambda$ 型の渦から ヘアピン渦への発達が観察できるが、(b)では $\Lambda$ 型の渦が発生 しているが水の場合のようなはっきりとしたへアピン渦の ヘッドの立ち上がり現象は見られない。Fig.4ではFig.3に比 べて流れ方向波長の短い $\Lambda$ 型の渦が発生している。

4-3 速度変動の分布 陰極線の下流方向位置が $x=500 \mathrm{~mm}$. $\mathrm{x}=700 \mathrm{~mm}$ での対称面 $(\mathrm{z}=0 \mathrm{~mm}, \mathrm{x}-\mathrm{y}$ 面)に拉りる速度分布と乱れ 強さの測定結果をそれぞれ Fig.5 から Fig.8 に示す。Fig.5 で 界面活性剤水溶液は $\mathrm{y}=10 \mathrm{~mm}$ のあたりで $\mathrm{u}_{\mathrm{ave}}$ Uが 1 を超えて おり、界面活性剂水溶液は水に比べワイヤーの影響を強く受 けるものと思われる。Fig.6より $6 \mathrm{~Hz}$ の場合の界面活性剤水 溶液は上流での速度分布の影響がまだ残っていると思われ る。また Fig.7 では水と界面活性剂水溶液とはあまり違いが 見られないが、Fig.8では $2 \mathrm{~Hz}$ の場合の界面活性剤水溶液は 水に比べて乱れ強さが大きくなっている。Fig.9に対称面 ( $\mathrm{z}=0 \mathrm{~mm}, \mathrm{x}-\mathrm{y}$ 面 $)$ における各点での $\mathrm{x}$ 方向変動速度成分 $\mathrm{u}^{\prime}$ を無 次元化したものの等值線図を示寸。図中では白い領域ほど平 均流速より瞬間流速が高く、逆に黒い領域ほど流速が低く なっている。界面活性剂水溶液では水に比べて速度変動の規 則性がより強く、乱流への遷移がより緩慢に進行していると 思われる。

\section{5. 結言}

せん断誘起状態における界面活性剤水溶液では、水に比べ てより緩慢に遷移が進行する。

\section{6. 参考文献}

(1) Ohlendorf,D.,Interthal,W.\&Hoffmann,H.1986"Surfactant system for drag reduction:physico-chemical properties and rheological behavior", Rheol.Acta,25,468-486.

Fig. 1 Apparatus 


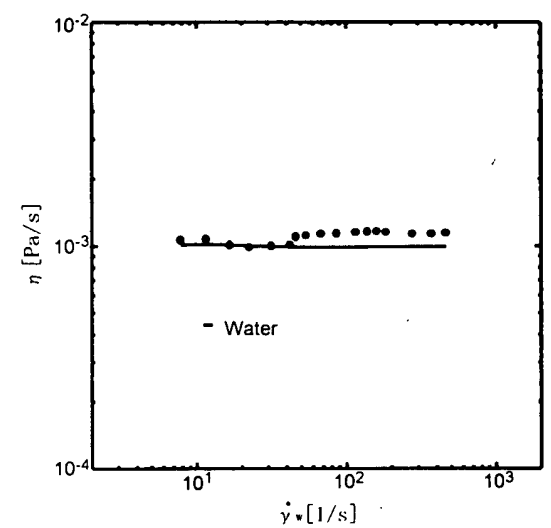

Fig. 2 Shear viscosity

(C14TASal(Br) $400 \mathrm{ppm}, d=5 \mathrm{~mm}, T=20.6^{\circ} \mathrm{C}$ )

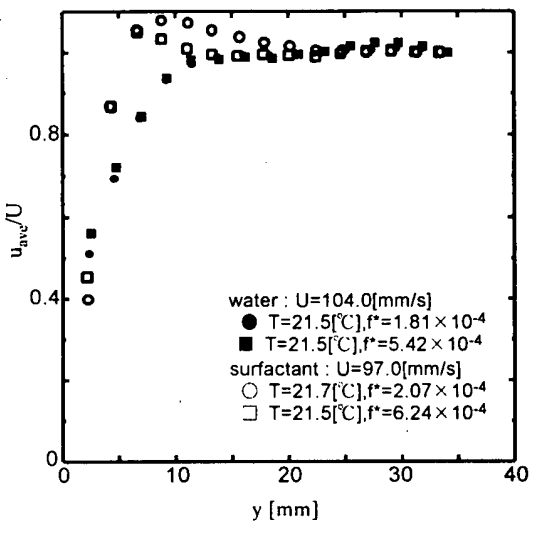

Fig. 5 Velocity profile $(x=500[\mathrm{~mm}], z=0[\mathrm{~mm}])$

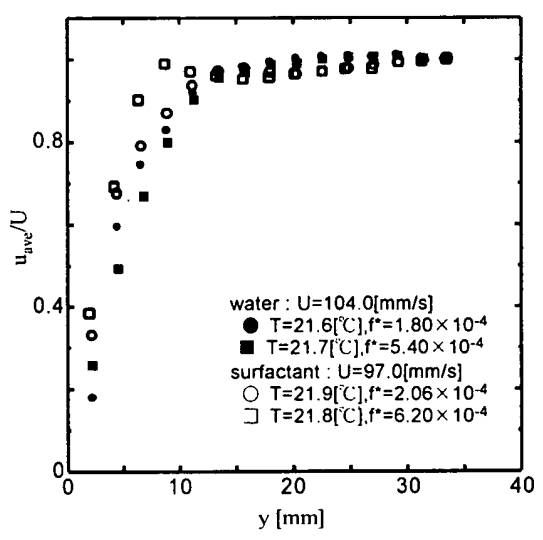

Fig.6 Velocity profile $(x=700[\mathrm{~mm}], z=0[\mathrm{~mm}])$

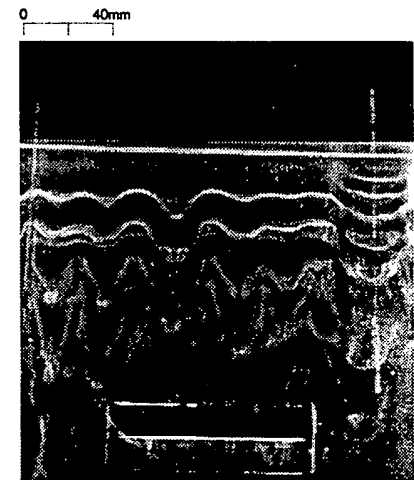

(a) water. $U=104.0 \mathrm{~mm} / \mathrm{s}$

$\mathrm{T}=20.8^{\circ} \mathrm{C}, \delta,=10.9 \mathrm{~mm}$

$\operatorname{Re}_{x}=5.23 \times 10^{4}, \mathrm{ft}^{\mathrm{*}}=1.84 \times 10^{-4}$

Fig. 3 Disturbances by a vibrating wire (bird view)

(b) $\mathrm{C}: 4 \mathrm{TASal}(\mathrm{Br}), \mathrm{U}=97.0 \mathrm{~mm} / \mathrm{s}$ $\mathrm{T}=19.6^{\circ} \mathrm{C}, \delta,=11.5 \mathrm{~mm}$

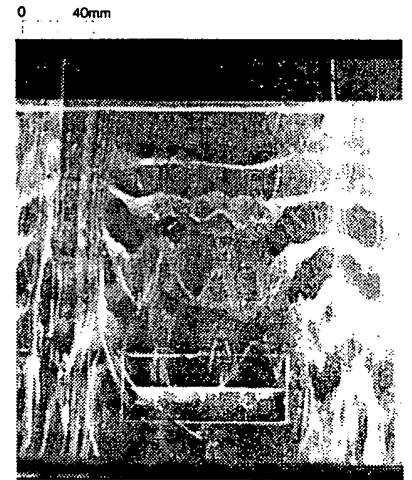

$f^{*}=2.18 \times 10^{-4}$ $x=500 \mathrm{~mm}, y=3 \mathrm{~mm}$

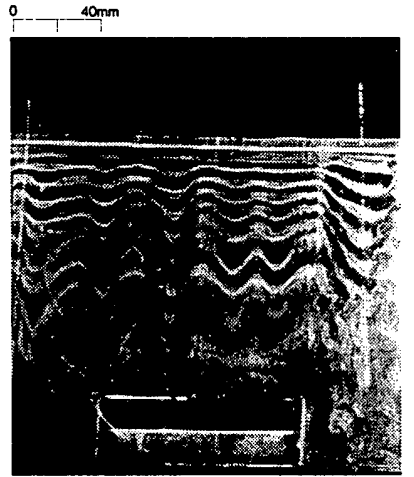

(a) water, $U=104.0 \mathrm{~mm} / \mathrm{s}$ $T=20.9^{\circ} \mathrm{C}, \delta,=10.9 \mathrm{~mm}$ Rex $=5.24 \times 10^{4}, f^{\circ}=5.50 \times 10^{-4}$

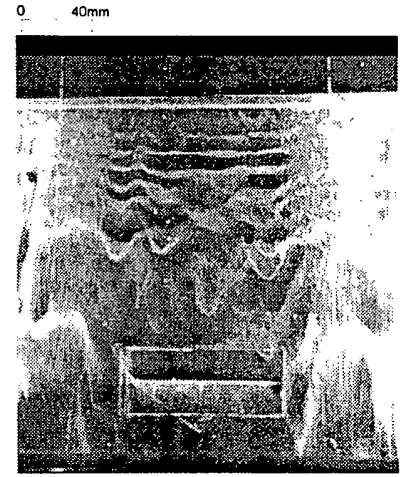

(b) C14TASal(Br), U $=97.0 \mathrm{~mm} / \mathrm{s}$ $\mathrm{T}=20.0^{\prime} \mathrm{C}, \delta,=11.4 \mathrm{~mm}$ $R_{\mathrm{x}}=4.78 \times 10^{4}, \mathrm{f}^{*}=6.47 \times 10^{-4}$

Fig.4 Disturbances by a vibrating wire (bird view) $x=500 \mathrm{~mm}, y=3 \mathrm{~mm}$

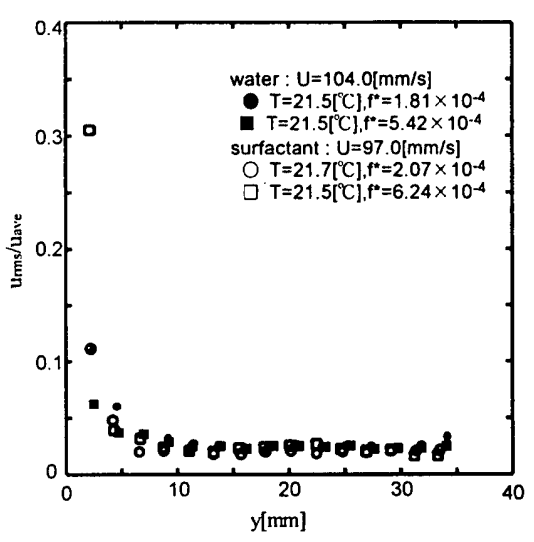

Fig. 7 Relative intensity of turbulence $(x=500[\mathrm{~mm}], z=0[\mathrm{~mm}])$

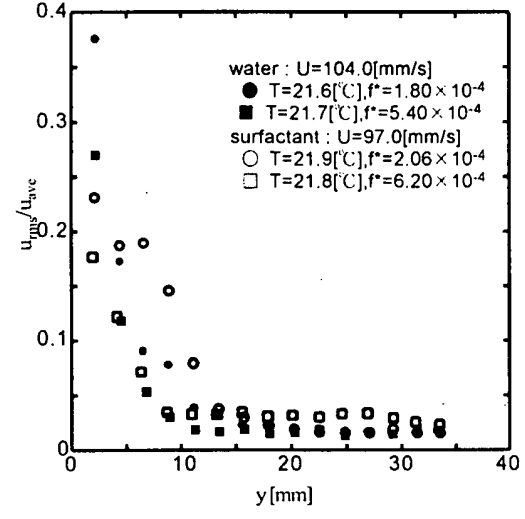

Fig. 8 Relative intensity of turbulence $(x=700\{\mathrm{mnn}], z=0[\mathrm{~mm}])$

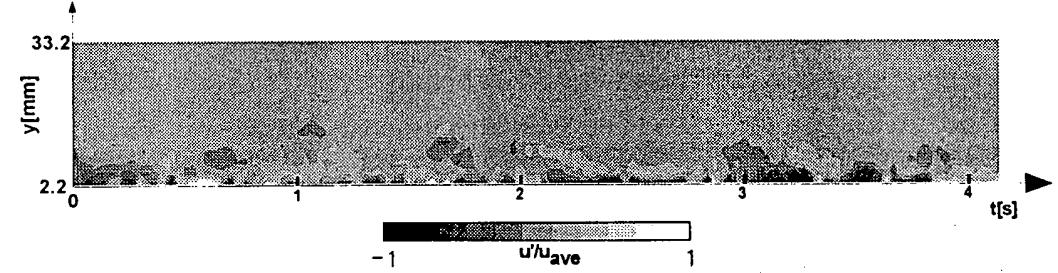

(a) water

$T=21.6\left[{ }^{\circ} \mathrm{C}\right], f^{*}=1.80 \times 10^{-1}$

$\mathrm{U}=104.0 \mid \mathrm{mm} / \mathrm{s}], \mathrm{x}=700[\mathrm{~mm}], \mathrm{z}=0|\mathrm{~mm}|$

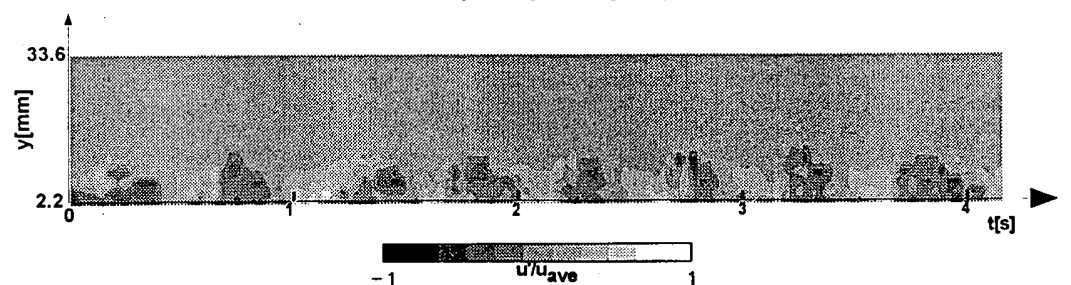

(b) aqueous surfactant solution

$\mathrm{T}=\left.21.9\right|^{\circ} \mathrm{C} \mid, \mathrm{f}^{*}=2.06 \times 10^{-4}$

$U=97.0[\mathrm{~mm} / \mathrm{s}], x=700[\mathrm{~mm}], z=0[\mathrm{~mm}]$

Fig.9 Contour plot of fluctuating velocity 